\begin{tabular}{|c|c|c|}
\hline \multirow{2}{*}{ 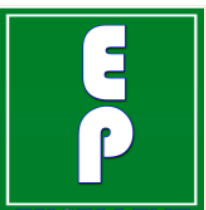 } & $\begin{array}{l}\text { International Journal of Current Research in } \\
\text { Biosciences and Plant Biology }\end{array}$ & $y=$ \\
\hline & Volume 6 • Number 4 (April-2019)・ISSN: 2349-8080 (Online) & \\
\hline $\begin{array}{l}\text { EXCELLENT } \\
\text { PUBLISHERS }\end{array}$ & Journal homepage: www.ijcrbp.com & \\
\hline
\end{tabular}

\title{
Evaluation of physicochemical and sensory properties of wine from Citrus maxima fruit
}

\author{
Anjana Prakash', Ancy Philip ${ }^{1}$, S. Archa1, C. V. Archana', Arathy G. Nair', \\ B. Arya ${ }^{1}$, K. R. Sabu ${ }^{2}$, B. R. Rajesh ${ }^{1}$ and Pratap R. Chandran ${ }^{*}$
}

${ }^{1}$ Department of Biotechnology and Research, K. V. M. College of Science and Technology, K.V.M. College Road, Kokkothamangalam P. O., Cherthala - 688583 , Alappuzha District, Kerala State, India

${ }^{2}$ Department of Chemistry, Arba Minch University, Abaya Campus, Arba Minch. P. B. No. 21, Ethiopia

*Corresponding author; e-mail: drpratapchandran@yahoo.co.in

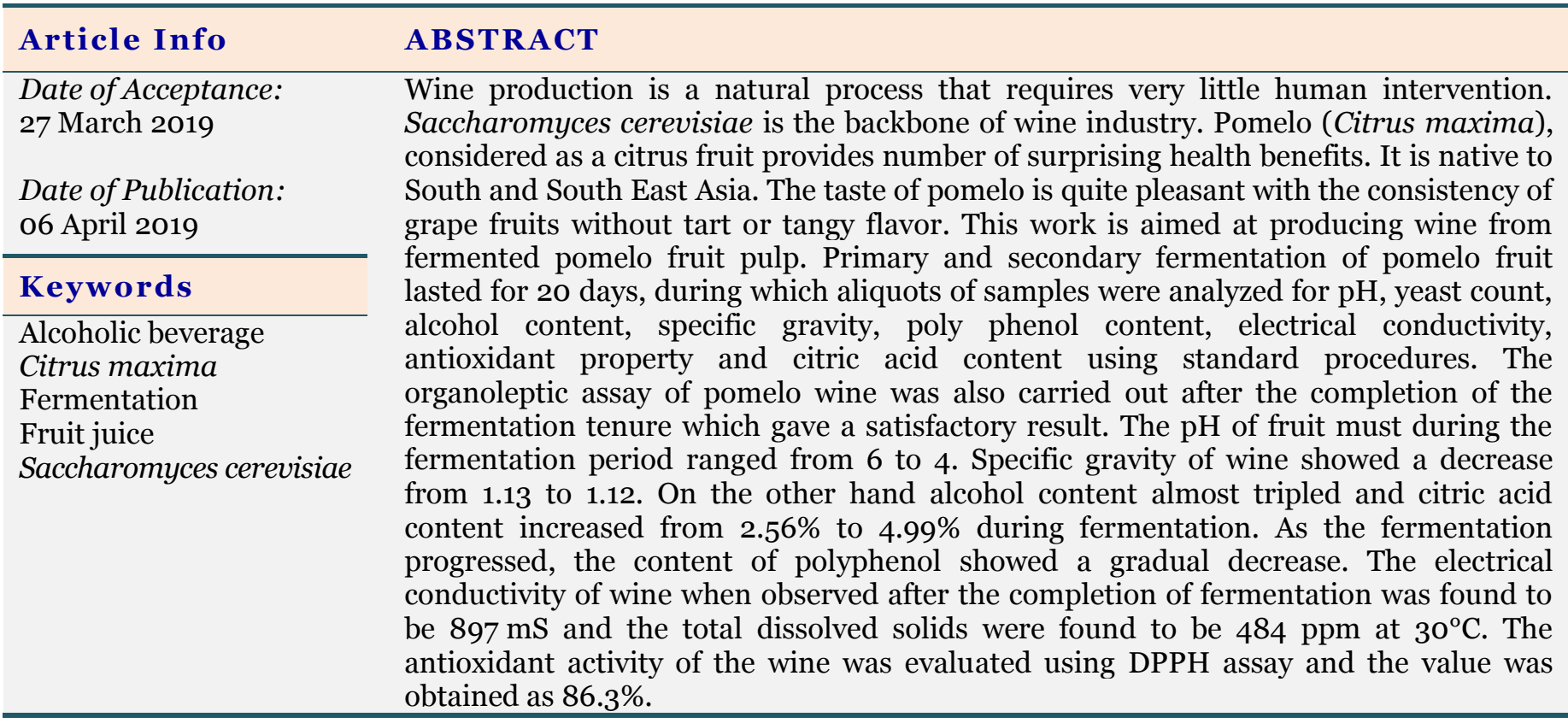

\section{Introduction}

Wine is an alcoholic beverage made from fermented fruit juice (Johnson, 1989). Yeast (Saccharomyces cerevisiae) consumes the sugar in the fruit juice and converts it to ethanol and carbon dioxide. Primary fermentation last for approximately one week, during which, most of the sugar present in the fruit juice gets converted to ethanol (McGovern et al., 2013). The excess yeast cells are then removed from the juice along with other sediments and a slower secondary fermentation is allowed to proceed to develop the final flavour. Sugar can be added to get the desired alcohol content or to modify the flavour. Grapes were commonly preferred for wine production because grape juice aids the fermentation process without the addition of 
sugars, acids, enzymes, or other nutrients. However, coconut sprout and fruits such as banana and pineapple were also subjected to fermentation to study the quality of wine formed (Mohan et al., 2018; Ajit et al., 2018).

Pomelo, Citrus maxima is a natural citrus fruit belonging to the family Rutaceae and is native to South East Asia. It tastes like a sweet, mild grape fruit. The pulp of pomelo contains considerable amount of sugar, thus making it suitable for wine production. Pomelo contains minerals and other components like vitamin $\mathrm{C}$, potassium, dietary fiber, vitamin B6, magnesium, folic acid, vitamin B1, iron, vitamin A, beta carotene, bioflavonoid, antioxidants and enzymes. Consuming this fruit has several health benefits such as preventing infection, boosting immunity, promoting healing, preventing anemia, warding off cold and flu, fights cancer and ageing, helping in weight loss as well as digestion, preventing osteoporosis and muscle cramps, controlling blood pressure, etc. (Singh and Gupta, 2017).

Pomelo fruit usually has a pale green to yellow colour. It is considered as the largest fruit in the citrus family, averaging a size larger as $30 \mathrm{~cm}$ in diameter and a weighs of 1-2 kg. The climatic conditions of tropic zone are suitable for the growth of pomelo (Kyndt et al., 2010). In general wine is an un distilled beverage which is so nutritive and even more tasty than the raw fruit itself. Upon fermentation the physicochemical and sensory qualities such as taste, flavor etc. of the fruit are modified due to the formation of certain compounds such as alcohol, organic acids, amino acids, etc. Fermentation for the production of beverages like wine depends on the ability of the yeast to convert sugar contents of the substrate to alcohol and esters. Moreover, the species of yeasts that develop during the fermentation determine the final characteristics (flavour, taste, aroma etc.) of the product. Wine has a greater acceptance than other ordinary drink (Yang and Wiegand, 1949). It is a beverage with greater shelf life and the alcohol present in it has antipathogenic effect (Oddbins, 2012). The organic content present in fruit pulp gives it characteristic odor, taste, smell, and other health benefits. Hence the present study was aimed to estimate the chemical constituents and the quality of wine produced from pomelo fruit using $S$. cerevisiae and spontaneous fermentation.

\section{Materials and methods}

\section{Microorganism used}

S. cerevisiae obtained from the culture collection of K.V.M College of Science and Technology, Cherthala, Alappuzha, Kerala, India was used for fermentation.

\section{Collection of sample}

Pomelo fruit (C. maxima) sample was obtained from Alappuzha district. About $1 \mathrm{~kg}$ of the fruit was taken, cleaned and the fruit pulp was extracted.

\section{Inoculum preparation}

Sterilized glucose yeast broth was inoculated with $S$. cerevisiae in a rotary shaker at $60 \mathrm{rpm}$ for 24 hours at $30^{\circ} \mathrm{C}$. Then it was centrifuged at 6000rpm at $4^{\circ} \mathrm{C}$ for 10 minutes for cell separation. The preinoculum was prepared by washing the cell twice and resuspending in normal saline to attain a concentration of $10^{8}$ cells $/ \mathrm{ml}$. 10ml of preinoculum was then transferred into $250 \mathrm{ml}$ Erlenmeyer flask containing $100 \mathrm{ml}$ pomelo juice. This mixture was used as inoculum. The incubation of the mixture was then carried out in a shaking incubator at 6orpm and then kept overnight at $30^{\circ} \mathrm{C}$.

\section{Preparation of must and fermentation}

Crushed pomelo fruit pulp was used as the substrate for the production of wine. About $100 \mathrm{~g}$ of sugar and $250 \mathrm{ml}$ water were mixed together to form a solution. To the sugar solution crushed pomelo fruit pulp (1 kg) was added and mixed well. A control was also prepared by mixing pomelo fruit pulp and sugar solution. The must as well as control were autoclaved at $121^{\circ} \mathrm{C}$ for 15 minutes at $15 \mathrm{lbs}$ and then cooled. The prepared inoculum of $S$. cerevisiae was added to the sample except the control followed by thorough mixing and kept at room temperature for fermentation.

The fermentation was carried out for 20 days in dark. During fermentation at an interval of 5 days, the sample and control were filtered by sieving through four layers of muslin cloth. The filtrate was used for conducting various analytical tests and the residues were discarded. The wine jar was 
immersed in water bath at $68-70^{\circ} \mathrm{C}$ in order to stop fermentation after the completion of the $2 \mathrm{O}^{\text {th }}$ day.

\section{pH}

$\mathrm{pH}$ of the wine samples were checked using a digital $\mathrm{pH}$ meter (Eutech CyberScan $\mathrm{pH}$ 510) precalibrated with buffers of $\mathrm{pH} 4$ and 7 (Ochai and Kolhatkar, 2008).

\section{Estimation of yeast cell count}

The increasing number of yeast cells ( $S$. cerevisiae), increases the turbidity of the sample. Optical density is parameter widely used to estimate the number of cells in a culture. Five $\mathrm{ml}$ of the wine sample was taken in a test tube along with a suitable blank. The absorbance was read using spectrophotometer at $600 \mathrm{~nm}$. The density of yeast cell at $600 \mathrm{~nm}$ is around $10^{7}$ cells per $\mathrm{ml}$.

\section{Determination of Total phenolic content}

The total phenolic content in wine was estimated by Folin-Ciocalteau method (Singleton and Rossi, 1965). About $1 \mathrm{ml}$ of the sample was taken as an aliquot. To this $1 \mathrm{ml}$ of Folin-Ciocalteau reagent was added and mixed for 3 minutes after which 1.0 ml of saturated sodium carbonate solution was added and the final volume was made up to $10 \mathrm{ml}$ with distilled water. The same procedure was repeated for the control too after which both tubes were kept in dark for 30 minutes. The colour intensity was then measured at $760 \mathrm{~nm}$ against the control which was taken as the blank. Calibration curves were drawn using gallic acid standard and total phenol content (TPC) were calculated.

\section{Specific gravity}

Estimation of specific gravity was done using specific gravity bottle (Ranganna, 1986). A $50 \mathrm{ml}$ specific gravity bottle was washed with distilled water and dried in an oven and cooled at room temperature, weighed and noted as W1. It was then filled with distilled water and surface of the bottle was cleaned using cotton and was weighed again and the value was recorded as W2. After rinsing the bottle with 10ml of pomelo wine it was filled up to the brim with wine and weighed and the weight was noted as $\mathrm{W}_{3}$. The specific gravity of the wine sample was calculated using the formula:

$$
\text { Specific gravity }=\frac{W 3-W 1}{W 2+W 1}
$$

\section{Estimation of alcohol}

The estimation of alcohol was done using the iodoform test (Kulandaivel and Janarthanan, 2012). About $1 \mathrm{ml}$ of wine sample containing alcohol was taken in a test tube and 4 drops of $1 \mathrm{~N}$ sodium hydroxide was added to it. Concentrated solution of iodine was then added drop by drop until a faint yellow colour persisted. The tubes were allowed to stand for a minute and added excess amount of sodium hydroxide solution if excess colour developed. Shook the mixture well and allowed to stand for 2-3 minutes. A yellow coloured precipitate that was formed was found to settle at the bottom. Removed the precipitate at room temperature and weighed and calculated the amount of alcohol present in the sample.

\section{Determination of antioxidant activity}

The antioxidant activity of wine was estimated using 2,2-diphenyl-1-picrylhydrazyl (DPPH) assay (Soares et al., 1997). The method is based on the scavenging of DPPH by antioxidants, which upon reduction reaction decolorizes the methanol solution of DPPH. If DPPH radical accept an electron or hydrogen from antioxidant molecules it becomes a stable diamagnetic molecule and will change the colour to yellow. Lower the absorbance of the reaction mixture, higher the free radical scavenging activity. The wine sample measuring 5 ml was mixed with a solution of $5 \mathrm{ml}$ of $0.06 \mathrm{mM}$ $\mathrm{DPPH}$ in methanol and incubated in dark for 30 minutes. The absorbance was measured at $520 \mathrm{~nm}$. The capability to scavenge the DPPH radical was calculated using the equation:

$$
\text { RSA \% }=\frac{[1-(\text { Abs control }- \text { Abs sample })] \times 100}{\text { Abs control }}
$$

\section{Estimation of reducing sugar}

The concentration of reducing sugar was analysed according to the following method (Saqib and Whitney, 2011). DNS reagent was prepared by dissolving $1 \mathrm{~g}$ of DNS and $30 \mathrm{~g}$ of sodium potassium tartaric acid in $80 \mathrm{ml}$ of $0.5 \mathrm{~N}$ sodium hydroxide solutions. For the complete dissolution 
of reagents the solution was kept at $45^{\circ} \mathrm{C}$ and cooled down to room temperature and made up to $100 \mathrm{ml}$ with distilled water. Then the solution was kept at $4^{\circ} \mathrm{C}$ for two weeks. In order to estimate the reducing sugar $0.4 \mathrm{ml}$ of DNS reagent was added to $0.1 \mathrm{ml}$ of sample and kept at $95^{\circ} \mathrm{C}$ for 5 minutes in a water bath for incubation, after which the absorbance was measured spectroscopically at 540 nm.

\section{Titratable acidity}

Titratable acids represent the sum of all acids in the wine and titratable acidity corresponds to the percentage of citric acid and the latter was determined by the method of AOAC (1995). Titration with indicator phenolphthalein is usually done to estimate the content of citric acid in wine.10 $\mathrm{ml}$ of wine sample was pipetted into a conical flask, few drops of the indicator was then added. It is then titrated against the solution of sodium hydroxide taken in the burette till the colour of the wine sample changed to pink.

Weight of citric acid in $1000 \mathrm{ml}$ of sample $=$ normality $X$ volume $X$ equivalent weight 1000

\section{Determination of electrical conductivity}

Total dissolved ionic solids (TDS) such as salt and minerals increase the electrical conductivity (EC) of a solution. The EC and TDS were determined using electrical conductivity meter (Systronics 308).

\section{FTIR spectroscopy}

Fourier Transform Infrared Spectrophotometer (FTIR) is a powerful technique used to identify the chemical bond present in a compound. By interpreting IR spectrum obtained, the chemical bonds in a compound can be analysed. The tablet for spectroscopy (FTIR Shimadzu prestige21) were prepared in agate mortar, by mixing a drop of wine sample with $\mathrm{KBr}(1: 100 \mathrm{p} / \mathrm{p})$ absorption spectra were measured between 400 and $4000 \mathrm{~cm}^{-1}$.

\section{Organoleptic assay}

After the completion of $20^{\text {th }}$ day of fermentation, wine samples collected from the fermentation flask were filtered and subjected to sensory evaluation. The panel comprised of different people recruited from members of the staff committee. The aim of choosing different panelist was because of difference in the sensibility of various assessors. The characters such as taste, odour, flavor, clarity and the overall acceptance of wine were assessed by 5 point hedonic scale (Espinoza et al., 2005).

\section{Results and discussion}

Wine is an important fermented product made from fruits since ancient times. Consuming wine on a regular basis results in health benefits and also it has a long shelf life. Throughout the fermentation period wine retains the acidic nature. Acidity increased during the fermentation period and the $\mathrm{pH}$ ranged from 5.7 to 4.5 (Table 1 ). The content of alcohol present in pomelo wine also showed an increasing trend that ranged from o to $7 \%$. As the fermentation proceeds the yeast cell count decreased to $2.35 \times 10^{6}$ from $8.1 \times 10^{6}$. Using spectrometer the initial value was measured to be $8.10 \times 10^{6}$ on the first day, then it attained a maximum value of $9.20 \times 10^{6}$ on the $5^{\text {th }}$ day and then decreased to $2.35 \times 10^{6}$ on the $20^{\text {th }}$ day (Fig. 1).

Table 1. Physicochemical analysis.

\begin{tabular}{llllll}
\hline $\begin{array}{l}\text { Physico- } \\
\text { chemical } \\
\text { parameters }\end{array}$ & $\begin{array}{l}\text { Day } \\
\text { o }\end{array}$ & $\begin{array}{l}\text { Day } \\
\text { 5 }\end{array}$ & $\begin{array}{l}\text { Day } \\
\mathbf{1 0}\end{array}$ & $\begin{array}{l}\text { Day } \\
\mathbf{1 5}\end{array}$ & $\begin{array}{l}\text { Day } \\
\mathbf{2 0}\end{array}$ \\
\hline $\begin{array}{l}\text { pH } \\
\begin{array}{l}\text { Alcohol content } \\
\text { (\%) }\end{array}\end{array}$ & Nil & 2.8 & 5.1 & 4.8 & 4.5 \\
$\begin{array}{l}\text { Specific gravity } \\
\text { (g/cm } 3 \text { ) }\end{array}$ & Nil & 1.13 & 1.13 & 1.12 & 1.12 \\
$\begin{array}{l}\text { Titratable } \\
\text { acidity (g/L) }\end{array}$ & Nil & 2.56 & 2.97 & 3.8 & 4.99 \\
\hline
\end{tabular}

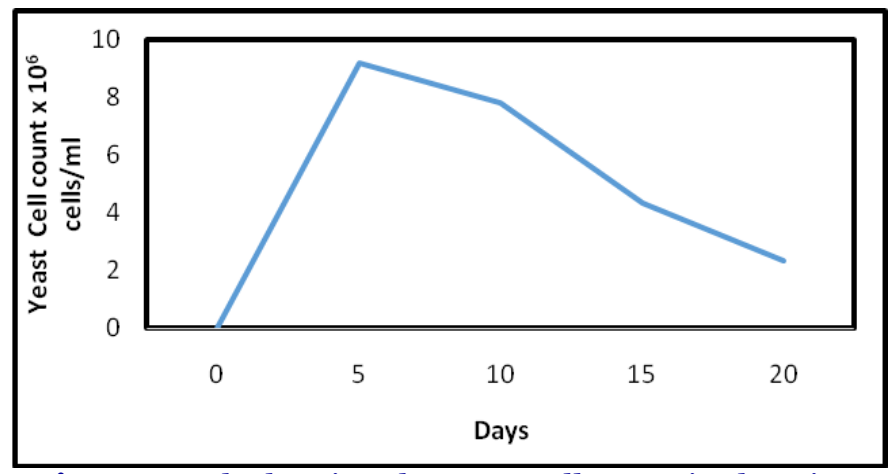

Fig. 1: Graph showing the yeast cell count in the wine sample. 
During the course of fermentation, specific gravity of pomelo wine decreased from 1.13 to 1.12. As the day passes by, the citric acid content increased. The initial value was found to be $2.56 \%$ on the $5^{\text {th }}$ day and it increased to $4.99 \%$ on the final day. Citric acid content showed an increasing trend during fermentation. From the estimation we get a decreased value from polyphenol content from 2.49 to 1.97 (Fig. 2). During wine ageing the decrease in phenolic content was observed due to polymerization of phenolic components present in the wine. Antioxidant content of the pomelo wine was evaluated using DPPH assay and the value was obtained as 86.31. Concentration of the reducing sugars declined as the fermentation proceeded. Reduction in sugar content was due the production of alcohol by the yeast cell. Electrical conductivity of the wine was read immediately after the completion of the $20^{\text {th }}$ day using conductivity TDS meter and it was found to be $897 \mathrm{mS}$. This value is used to estimate the extent of dissolved solids and it was found to be $484 \mathrm{ppm}$ at $30^{\circ} \mathrm{C}$.

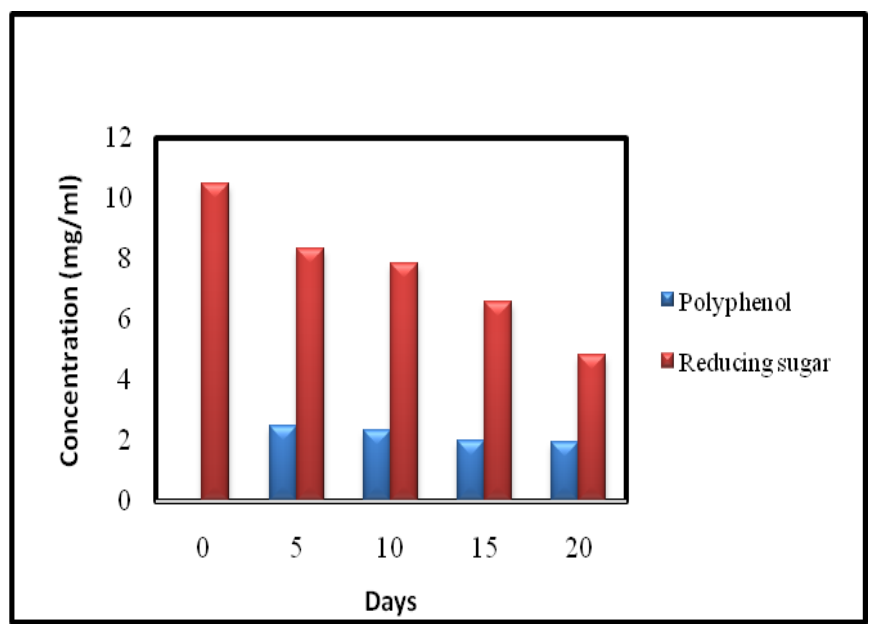

Fig. 2: Graph showing the polyphenol and reducing sugar content.

Decreasing trend of the $\mathrm{pH}$ found during the course of fermentation is due to organic acid production by the yeast (Okemini and Igwebike-Ossi, 2017). Specific gravity of wine decreased after fermentation. This helps to reduce the soluble solids in the wine and hence alcohol content increases during fermentation. Yeast present in wine utilized the sugar content and thereby reduces the soluble solids (Onwuka and Awam, 2001). Titratable acidity increases due to the metabolic activity of yeast present in the must (Akubor et al., 2003). The organoleptic assay was carried out on the completion of the fermentation process. A panel of people having varying sensibility was selected to test characters such as taste, odor, flavor, clarity and overall acceptance of wine. Estimation of organoleptic characters showed that the pomelo wine has a good acceptance (Fig. 3).

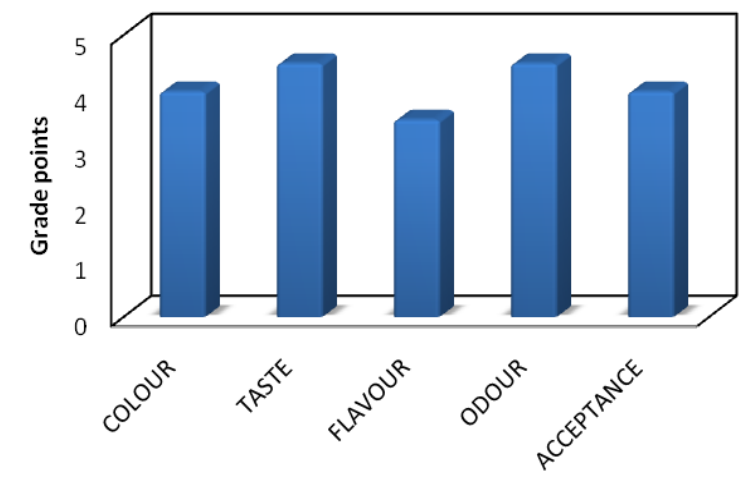

Fig. 3: Graph showing the organoleptic characteristics of the wine sample.

The $C$. maxima fruit juice before fermentation contains, as is evidenced from the FTIR spectrum, some of the marker bands of glucose, fructose and sucrose which correspond to the spectral range between 900 and $1400 \mathrm{~cm}$ inverse. The bands in the region 900 and $1153 \mathrm{~cm}$ inverse are assigned to $\mathrm{C}-\mathrm{O}$ and $\mathrm{C}-\mathrm{C}$ stretching modes while those in the $1199-1400 \mathrm{~cm}$ inverse region are due to O-C-H, C$\mathrm{C}-\mathrm{H}$ and $\mathrm{C}-\mathrm{O}-\mathrm{H}$ bending vibrational modes of the carbohydrates. Higher sucrose level in the juice is evidenced by the intense marker band of sucrose at $993 \mathrm{~cm}$ inverse. Regarding the functional groups of citric acid, which is a tricarboxylic acid, the FTIR spectrum shows $\mathrm{O}-\mathrm{H}$ stretching bands at 3275$3298 \mathrm{~cm}$ inverse region along with $\mathrm{C}-\mathrm{H}$ stretching at 2920-2924 cm inverse. Correspondingly $\mathrm{C}=\mathrm{O}$ stretching is expected at about 1717-1732 cm inverse, which is not well evidenced. However, at the same time, strong $\mathrm{C}=\mathrm{O}$ stretch has been observed at $1641 \mathrm{~cm}$ inverse and $1581 \mathrm{~cm}$ inverse. Similarly, - $\mathrm{CH} 2$ vibrations are observed at $1413 \mathrm{~cm}$ inverse, 1348 $\mathrm{cm}$ inverse and $1274 \mathrm{~cm}$ inverse. Nevertheless, the C-O-H or C-O-R vibrations at 1011, 1026 and 1045 $\mathrm{cm}$ inverse are missing, which clearly indicates that the citric acid molecules are not existing in the free state or even in the esterified state, rather there is a possibility of them existing in the citrate salt form (either of calcium or magnesium) (Fig. 4). 


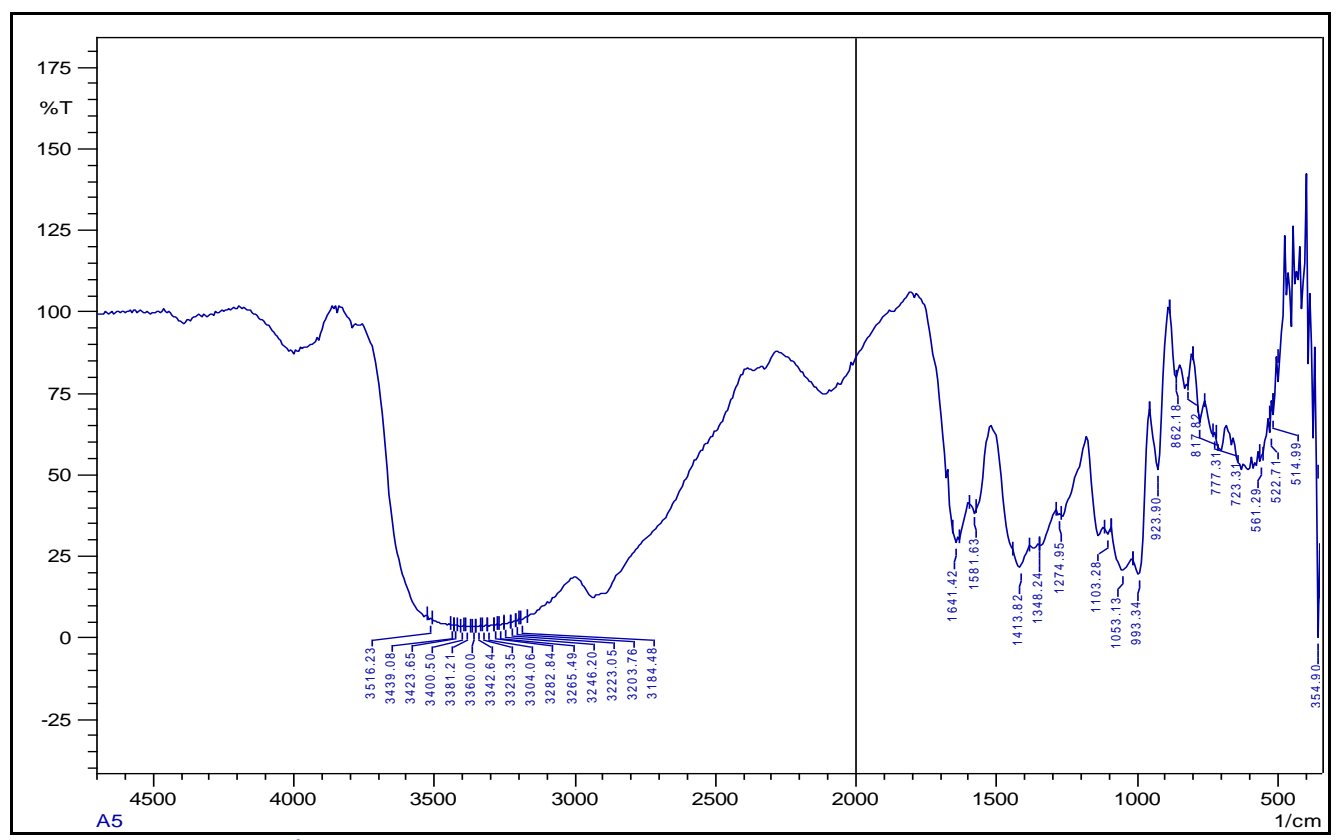

Fig. 4: FTIR spectrum of unfermented fruit sample.

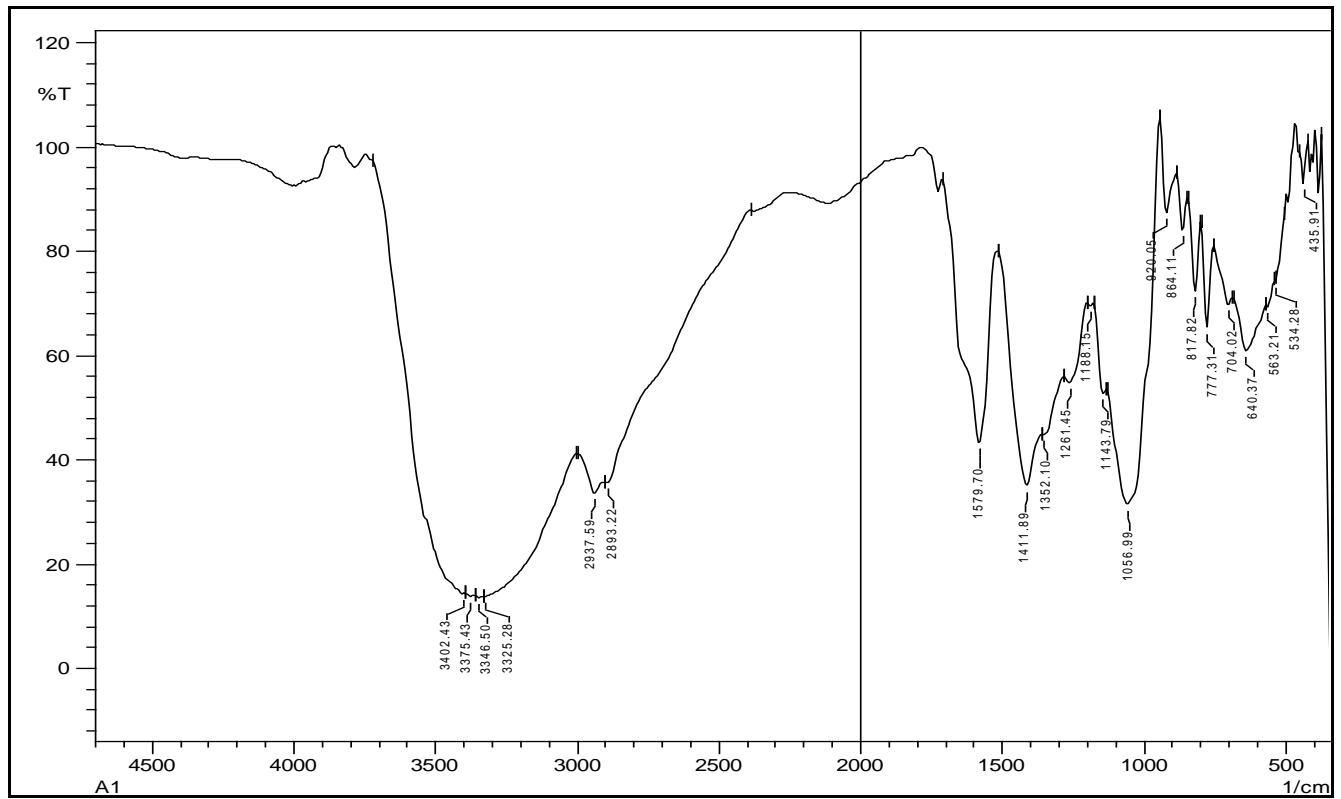

Fig. 5: FTIR spectrum of fermented fruit sample.

The most notable change observed after fermentation is the appearance of a strong absorption band at $1056 \mathrm{~cm}$ inverse due to the formation of ethyl alcohol, which corresponds to the $\mathrm{C}-\mathrm{O}$ stretching vibrations, along with $\mathrm{O}-\mathrm{H}$ stretching vibrations around $3400 \mathrm{~cm}$ inverse and $\mathrm{C}-\mathrm{H}$ stretching vibrations at about $2937 \mathrm{~cm}$ inverse. More important is the diminishing of the strength of the marker band at $993 \mathrm{~cm}$ inverse due to sucrose which indicates the conversion of sucrose to ethyl alcohol during fermentation. Other peaks related to $\mathrm{C}=\mathrm{O}$ stretching vibrations at 1579 $\mathrm{cm}$ inverse and - $\mathrm{CH}_{2}-$ and or $-\mathrm{CH}_{3}$ stretching vibrations at $1411 \mathrm{~cm}$ inverse, $1352 \mathrm{~cm}$ inverse and $1261 \mathrm{~cm}$ inverse remain intact, which indicates that the citrate components are unaffected by the process of fermentation. Broader peaks between $3325 \mathrm{~cm}$ inverse and $3300 \mathrm{~cm}$ inverse are due to the presence of $-\mathrm{OH}$ stretching, which could be a combined contribution from citrate hydroxyl and water hydroxyl, both showing strong intermolecular hydrogen bonding (Fig. 5). 


\section{Conclusion}

After 20 days of fermentation wine from pomelo with nutritional values was obtained and it is a good alcoholic beverage providing numerous health benefits. It contains moderate amounts of antioxidants and polyphenols which can protect cell from damage during oxidative stress and also protect against variety of disease such as heart disorder, cancer etc. Citric acid content is also high. Citric acid gives energy for cellular functions. The sensory evaluation such as taste, smell, flavour also gave acceptable value. So the pomelo wine is good for use and it has better beneficial effects on health. Normally the pomelo fruit has a slight bitter and sour taste and so people avoid eating raw fruit. But from the sensory evaluation of pomelo wine we received a positive response, so the wine is more acceptable than the raw fruit.

\section{Conflict of interest statement}

Authors declare that they have no conflict of interest.

\section{Acknowledgement}

The authors sincerely thank Dr. V.V. Pyarelal, Director, K.V.M. College of Science and Technology, Cherthala, Kerala, India, for providing necessary facilities and support for conducting this research work.

\section{References}

Ajit, E.J., Dilna, D., Farook, F., Promod, A., Kumar, B.M.S., Blesy, V.J., Sabu, K.R., Rajesh, B.R., Chandran, P.R., 2018. Preparation of wine from fruits of Musa accuminata and Ananas comosus; its physicochemical analyses and sensory evaluation. Int. Food. Nutr. Metabol. 5(6), 1-5.

Akubor, P.I., Obio, S.O., Nwadomere, K.A., Obiomah, E., 2003. Production and quality evaluation of banana wine. Plant Food Hum. Nutr. 58 (3), 1-6.

AOAC., 1995. Official Methods of Analysis. Washington 16. Ch.28, pp.3-16.

Espinoza, Y.R., Lopez, E.V., Sanchez, H.H., 2005. Characterization of a wine-like beverage obtained from sugar cane juice. World J. Micro. Biotech. 21, 447-452.
Johnson, H., 1989. Vintage: The Story of Wine. Simon and Schuster. pp. 11-66.

Kulandaivel, S., Janarthanan, S.P., 2012. Practical Manual of Fermentation Technology. I. K. International Publishing house Pvt. Ltd. New Delhi. 116-117.

Kyndt, T., Dung, T.N., Goetghebeur, P., Toan, H.T., Gheysen, G., 2010. Analysis of ITS of the rDNA to infer phylogenetic relationship among Vietnamese Citrus accessions. Genet. Resour. Crop. Evol. 57, 183-192.

McGovern, Patrick, E., Luley, B.P., Rovira, N., Mirzoian, A., Michael, P., Callahan, Smith, K.E., Hall, G.R., Davidson, T., Henkin, J.M., 2013. Fermented beverages of pre- and protohistoric China. P. Nat. Acad. Sci. 101 (51), 17593-17598.

Mohan, S.M.R., Sayoojya, K.P., Souparnika, A.P., Sowparnika, K., Pournami, T.S., Sabu, K.R., Rajesh, B.R., Chandran, P. R., 2018. Production of coconut sprout wine using Saccharomyces cerevisiae and its physicochemical analysis. J. Food Process. Tech. 6 (5), 445-449.

Ochai, J.O., Kolhatkar, A., 2008. Med. Lab. Sci. Prac. Tata McGrew Hill Pub. Ltd. New Delhi. pp.50-53.

Oddbins., 2012. Dict. Wine. London. Blooms. Pub. Ltd., Credo Web.

Okemini, O. F., Igwebike-Ossi C.D., 2017. Physicochemical properties and sensory evaluation of wine produced from Tiger Nut (Cyperus esculentus). Inter. J. Chem. Tech. Res. 10 (12), 155-164.

Onwuka, U., Awam, F.N., 2001. The potential for baker's yeast (Saccharomyces cerevisiae) in the production of wine from banana, cooking banana and plantain. Food Serv. Tech. 1(34), 127-132.

Ranganna, S., 1986. Handbook of Analysis and Quality Control for Fruit and Vegetable Products. Tata McGraw-Hill Pub. Company, New Delhi, India. pp. 124-125.

Saqib, A.A.N., Whitney, P. J., 2011. Differential behaviour of the dinitrosalicylic acid (DNS) reagent towards mono- and disaccharide sugars. Biomass Bioenergy 35, 4748-4750.

Singh, T.J., Gupta, T., 2017. Performance of successful combination of the fruits of wild pomegranate (Punica granatum L.) in Himachal Pradesh. J. Plant. Develop. Sci. 9(9), 885- 887. 
Singleton, V. L., Rossi, J.A., 1965. Colorimetry of total phenolics with phosphomolybdic phosphotungstic acid reagents. Amer. J. Enol. Viticult. 16, 144-158.

Soares, J.R., Dins, T.C.P., Cunha, A.P., Almeida, L.M., 1997. Antioxidant activity of some extracts of Thymus zygis. Free Rad. Res. 26, 469-478

Yang, H.Y., Wiegand, E.H., 1949. Production of fruit wines in the Pacific Northwest. Fruit Prod. J. Am. Food Manuf. 29, 8-12, 27, 29.

\section{How to cite this article:}

Anjana, P., Ancy, P., Archa, S., Archana, C. V., Nair, A. G., Arya, B., Sabu, K. R., Rajesh, B. R., Chandran, P. R., 2019. Evaluation of physicochemical and sensory properties of wine from Citrus maxima fruit. Int. J. Curr. Res. Biosci. Plant Biol. 6(4), 24-31. doi: https://doi.org/10.20546/ijcrbp.2019.604.004 